\title{
Measurements of long-chain acylcarnitines and free fatty acids reflect tissue-specific insulin sensitivity
}

Konrade ${ }^{1}$, Makarova $E^{1,2}$, Vilks $K^{2}$, Makrecka- Kūka $\mathrm{M}^{1}$, Sevostjanovs $E^{2}$, Dambrova $\mathrm{M}^{1,2}$, Grinberga $\mathrm{S}^{2}$, Liepins $\mathrm{E}^{2}$

${ }^{1}$ Riga Stradins University, Riga, Latvia

2 Latvian Institute of Organic Synthesis, Laboratory of Pharmaceutical Pharmacology, Riga, Latvia

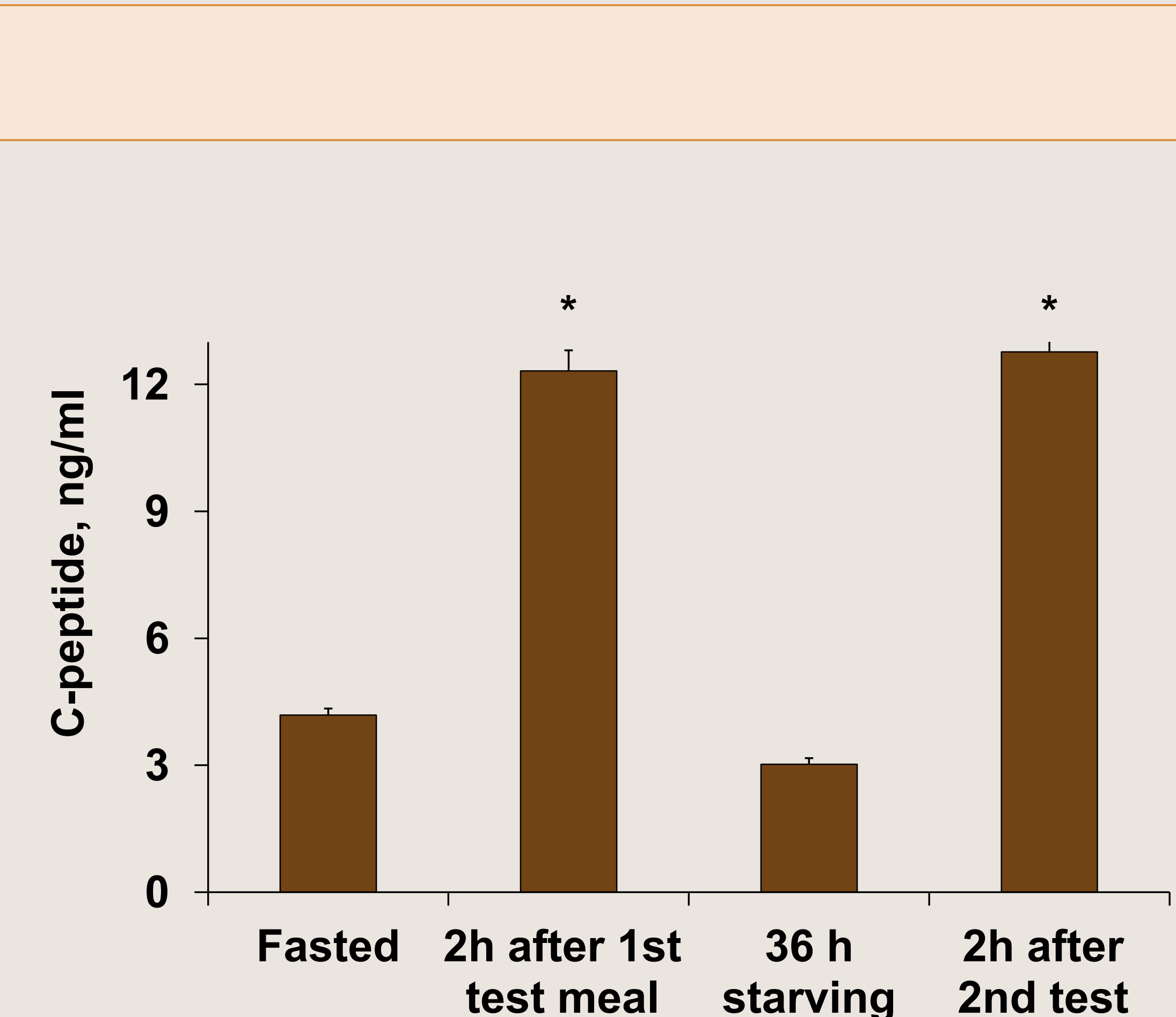

test meal starving 2 nd test

Despite the increased BMI, the traditional insulin resistance too HOMA-IR reflected a mild insulin resistance: $3.34(1.18,5.12)$ Test meal induced significant increase in C-peptide concentration by $3-4$ fold compared to fasted and starved state.

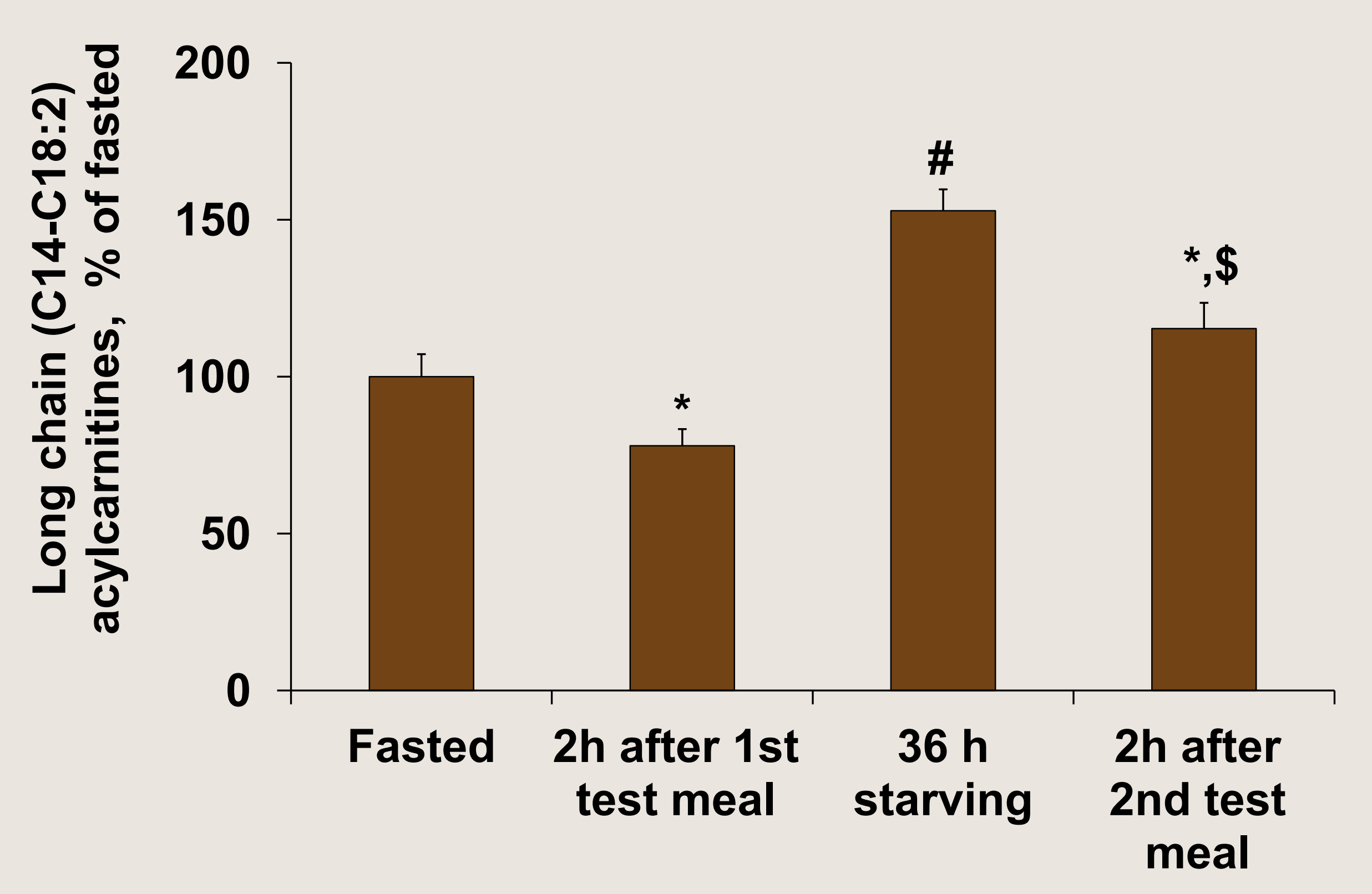

After 36 hour fasting acylcarnitine plasma concentration increased statistically significantly $1.5-2$ times. Two hours after meal long-chain acylcarnitine concentrations decreased by about $30 \%$.

\section{Results}

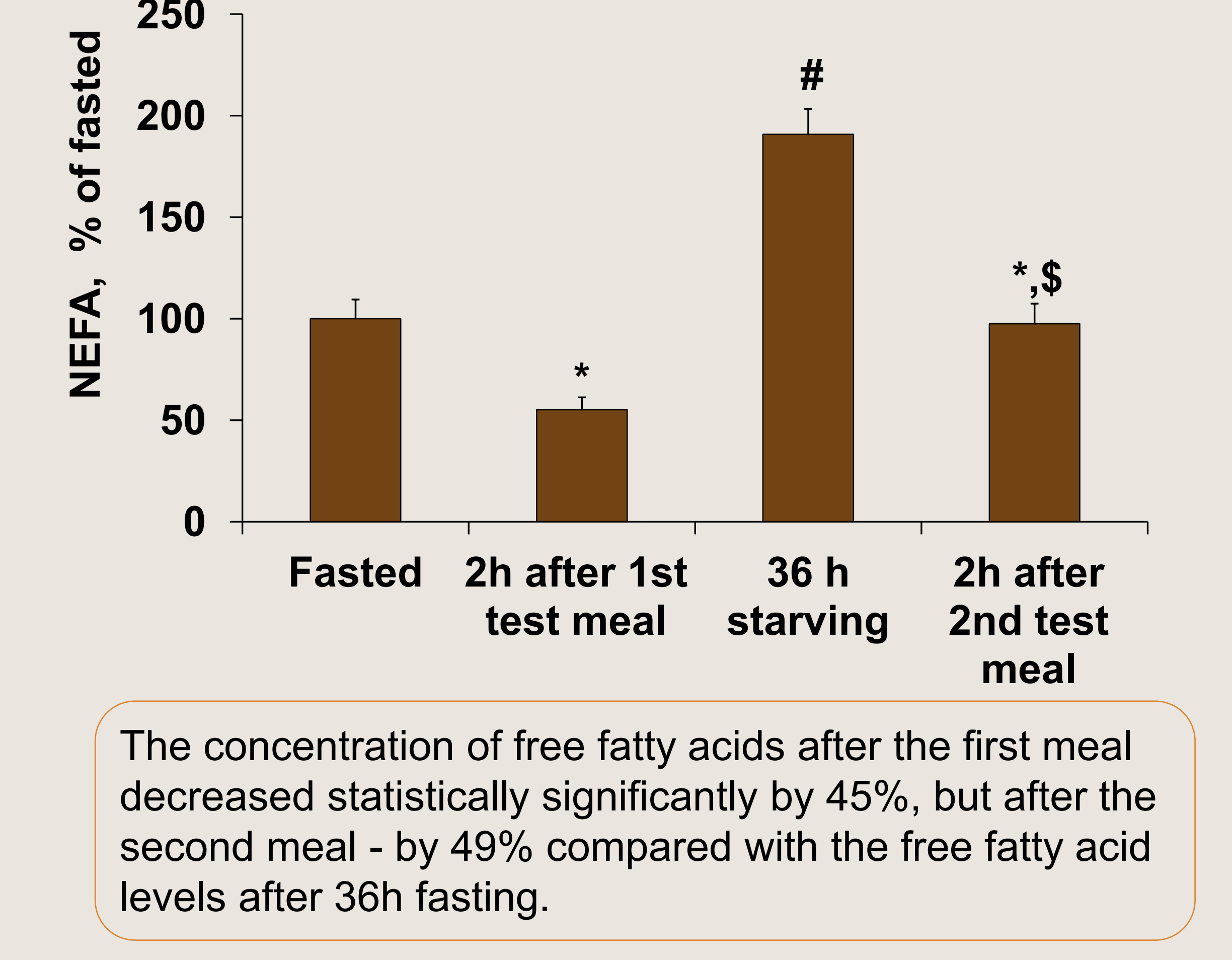

Metabolic flexibility

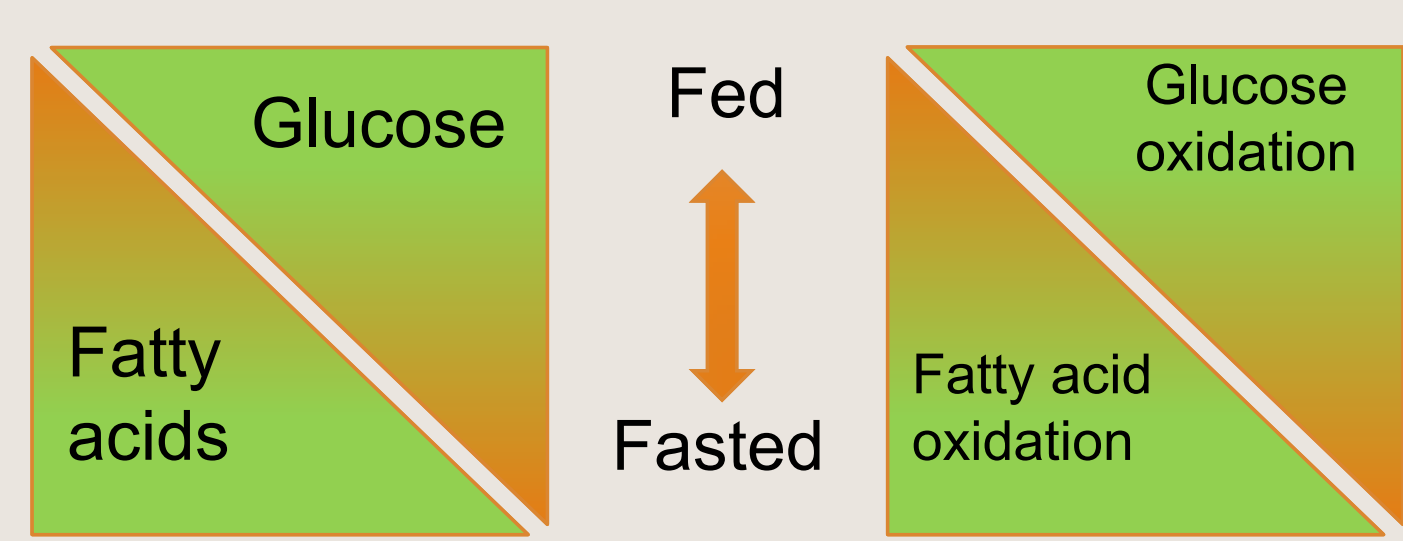

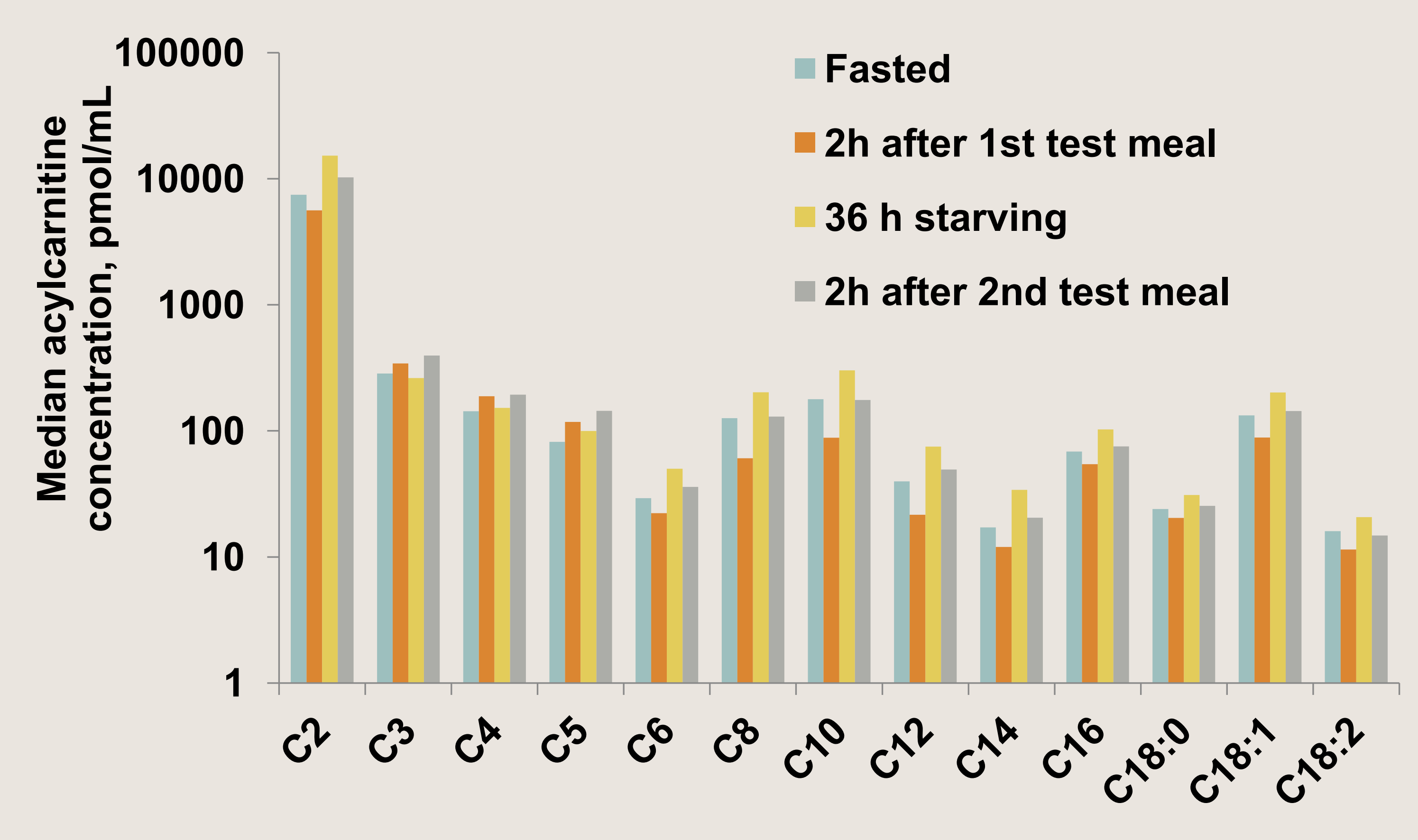

The higher insulin resistance, the lower was the postprandial decrease of C16 ( $\rho$ 0.56, $p=0.020), C 18: 0$ ( $\rho$ 0.69, $p=0.002), C 18: 1$ ( $\rho$ 0.55, $p=0.022)$, and $C 18: 2(\rho 0.60, p=0.012)$, but higher, was the increase of C18:0 ( $\rho$ 0.49, $p=0.047), C 18: 1$ ( $\rho 0.64, p=0.006)$, and C18:2 ( $\rho$ 0.59, $\mathrm{p}=0.013)$ after fasting. 